\title{
Beyond 9/11: health consequences of the terror attacks outside the USA
}

\author{
Xavier Bosch
}

Received: 2 November 2011 / Accepted: 28 November 2011/Published online: 11 December 2011 (c) SIMI 2011

The recent tenth anniversary of the $9 / 11$ attacks in the USA has resulted in much comment $[1,2]$. However, the health effects of bombings outside the USA following $9 / 11$ are not so well known, and may provide some lessons with implications for the preparedness of European, and developing cities and nations.

The 2002 Bali bombings in Indonesia killed 202 people, and the 2008 Mumbai attacks killed 164 and wounded over 300. Ten bombs on four trains caused 198 deaths and injured 2,312 in Madrid on 11 March 2004-the most serious European peacetime incident. On 7 July 2005, four bombs exploded in three London underground trains and a bus, killing 52 and wounding more than 775 .

All the attacks were deeply rooted in radical Islamist sentiments, sometimes exacerbated by local tensions, such as the India-Pakistan conflict in Mumbai. Yet, regardless of its origin, terrorism has devastating effects on the physical, mental, and social health of those affected, leading to growing concern in improving responses and preventive measures. The $9 / 11$ bombings and the subsequent related attacks in other countries marked a before and after in the history of international terrorism and its health consequences that deserve special attention and reflection.

The post-9/11 attacks were characterized by the unusual strains imposed on health systems unfamiliar with mass casualty incidents. All the explosions occurred in closed spaces, and three targeted crowded rush-hour commuter

\footnotetext{
X. Bosch ( $\square)$

Department of Internal Medicine, Institut d'Investigacions

Biomèdiques August Pi i Sunyer (IDIBAPS),

University of Barcelona, Hospital Clínic,

Villarroel 170, 08036 Barcelona, Spain

e-mail: xavbosch@clinic.ub.es
}

trains and buses, with closed train doors increasing immediate fatality rates. $93 \%$ of fatalities from the Madrid bombings were immediate, and most survivors had noncritical injuries. The wounds were most commonly in the head-neck and face, and blast lung injuries, mostly with positive outcomes, were frequent. Markers of critical injuries included earlobe amputations and upper thoracic spine fractures [3].

The size of the Madrid attack required mobilization of resources from various towns, and an unprecedented activation of regional and national command structures. Indeed, the European bombings provided unique opportunities to study cities' preparedness to deal with massive bomb attacks in crowded areas, and the immediate and subsequent health consequences. However, both countries already had experience with mass casualty management after earlier bombings linked to the Irish conflict in the UK and ETA in Spain, and had adopted some corrective actions after the Omagh bombing in 1998 in Northern Ireland [4] and the 1987 Hipercor bombing in Barcelona that killed 21 people and wounded 45 [5]. As a third-year medical resident, I was involved in treating many victims who were brought to the Emergency Department (ED) of the Hospital Clinic of Barcelona. Although a high level of medical care was maintained, the arrival of so many patients at once generated a situation where decisions had to be improvised, resulting in a somewhat chaotic atmosphere. This unfortunate experience led the hospital to examine its procedures for such situations, and to planning to ensure better preparation.

Various lessons have been learned from the attacks that occurred after 9/11. To cite a few salient examples, London experienced significant delays in initiating physical and psychological post-attack health follow-up, partly due to conflicting interpretations of the Data Protection Act, 
suggesting improvements in identifying and enrolling victims in health monitoring are required, since follow-up protocols could identify unrecognized public health problems [6].

In addition, a study evaluating pre-hospital and in-hospital responses to the London bombings suggests that mortality might be reduced by staged triage with unambiguous control of patient flow and resource use. Swift scene clearance may lead to high over-triage rates, and surges in casualty numbers [7].

Just 1 month after the London attacks, Ryan and Montgomery [8] suggest, in the New England Journal of Medicine, that doctors passing-by who became involved in in situ care require greater understanding of the emergency services workings, and training in new skills including rescue, triage, and transportation, since "the unique mechanisms of explosive injury and the combinations of primary, secondary, tertiary, and quaternary lesions in one person are not encountered in any other situation". Although this may seem somewhat overstated, later they correctly state that health services should be reviewed to ensure adequate training and equipment.

Furthermore, shortly after the Bali bombings, Fisher and Burrow [9], commenting on the evacuation of Australian victims to an Australian hospital, argue that, during a disaster of this type, in order to allow surgeons to concentrate on immediate surgical care of victims, other hospital physicians should regard themselves as a large, homogenous group able to work flexibly in the co-ordination of patient care and logistical aspects including which patients should be transferred and where. Similar to the Madrid attacks, patients from the Bali bombings were found to have unanticipated injuries such as multiple cerebral infarctions or a penetrating glass fragment injury to the vagus nerve.

Perhaps unsurprisingly, most studies of the post-9/11 attacks have dealt with the psychological consequences. For instance, 2 months after the Madrid bombings, psychopathological disorders, especially post-traumatic stress disorder, were 40 and 12 times more prevalent in victims and Madrid residents, respectively, than normal; 18 months later, the prevalence remained unchanged in the wounded but reverted to normal in residents [10].

Depressive symptoms were common in exposed persons during the first year after the 2004 Madrid bombing. Depression, anxiety disorders, and alcoholism had been reported in a previous controlled study involving 1,021 victims and relatives of ETA attacks [11], suggesting that studying the long-term effects of terrorist bombings on conditions such as alcoholism (and probably drug addiction) would be valuable.

The effects of the attacks following 9/11 on suicides were also examined. In particular, a brief but significant reduction in the daily suicide rate was unexpectedly observed in England a few days after the London attacks, possibly due to the observed government preparedness, the less-graphic television coverage compared with the traumatic scenes produced by $9 / 11$, and, perhaps, to increased social cohesion at a time of national threat [12]. Conversely, there was a three- to four-fold increase in suicide risk after the Bali bombings, probably linked to psychological, cultural, and spiritual factors [13].

Clearly, advances have been made in the USA in both emergency and routine responses. After 9/11, the government recognized the value of public health to the security of the nation, and increased investment to unheard levels. Although lessons may be drawn from the American experience, some worries remain. While governments should protect the lives of their citizens, public health funding should not be diverted to countering terrorism, particularly bioterrorism [14], especially when many fears voiced are unfounded or over-alarmist. Notably, in 2002, New York received US \$1.3 million to reduce heart disease, compared with $\$ 34$ million for bioterrorism preparedness. The cost of anti-terrorist initiatives in the UK also increased noticeably during 2007-2011: whether public health needs were affected is unclear.

The attacks in Europe did not lead, as in the USA, to major public health reforms, as the magnitude of the tragedies in London and Madrid was not comparable. However, in the succeeding years, close attention has been paid to the issue of mass casualty incidents, whatever the cause, with specific societal and health measures resulting in better preparedness [15].

While public health systems can now react more rapidly to threats, assigning priorities remains a challenge. In the USA, the anthrax attacks resulted in a vast increase in biodefense spending, especially on the building of new biosafety facilities, especially by the National Institute of Allergy and Infectious Diseases (NIAID). However, no new attacks have occurred, and some critics claim that NIAID has diverted funds (and researchers) from greater public health hazards and priorities, such as resistant strains of bacteria [16]. Equally, in 2004, the Project BioShield Act which provided billions of dollars to be spent on protecting against bioterrorism, has resulted in no new anthrax vaccine, and no answers to other potential threats, such as plague or Ebola.

More effective, evidence-based public health actions in dealing with potential emergencies resulting from terrorist attacks should ideally complement and reinforce the policies needed to reduce inter-emergency morbidity and mortality rates.

Finally, high poverty levels, unforeseen urban expansion, and lack of effective responses and recovery probably heighten the effects of terrorism in developing countries. In 
developed countries, economic loss suffered by victims' families is partly covered by private insurance, an option open to very few people in developing nations: Mumbai victims' families are unlikely to have received any indemnity. In these countries, increased expenditure on public security such as surveillance and counter-terrorism training diverts scarce investments away from promoting growth in healthcare, and for the eradication of poverty.

Conflict of interest None.

\section{References}

1. (2011) 9/11: new data, reviews, and reflections. Lancet 378:850

2. Inglesby TV (2011) Progress in disaster planning and preparedness since 2001. JAMA 306:1372-3. doi:10.1001/jama.2011. 1359

3. Turégano-Fuentes F, Caba-Doussoux P, Jover-Navalón JM et al (2008) Injury patterns from major urban terrorist bombings in trains: the Madrid experience. World J Surg 32:1168-1175

4. Lavery GG, Horan E (2005) Clinical review: communication and logistics in the response to the 1998 terrorist bombing in Omagh, Northern Ireland. Crit Care 9:401-408

5. GomezMorell PA, Escudero Naif F, Palao Domenech R, Sospedra Carol E, Bañuelos Roda JA (1990) Burns caused by the terrorist bombing of the department store Hipercor in Barcelona. PartI. Burns 16:423-425

6. Catchpole MA, Morgan O (2010) Physical health of members of the public who experienced terrorist bombings in London on 07 July 2005. Prehosp Disaster Med 25:139-144
7. Aylwin CJ, König TC, Brennan NW et al (2006) Reduction in critical mortality in urban mass casualty incidents: analysis of triage, surge, and resource use after the London bombings on July 7, 2005. Lancet 368:2219-2225

8. Ryan J, Montgomery H (2005) The London attacks-preparedness: terrorism and the medical response. N Engl J Med 353:543-545

9. Fisher D, Burrow J (2003) The Bali bombings of 12 October, 2002: lessons in disaster management for physicians. InternMed J $33: 125-126$

10. Ferrando L, Galea S, Sainz Cortón E et al (2010) Long-term psychopathology changes among the injured and members of the community after a massive terrorist attack. Eur Psychiatry 26. doi:10.1016/j.eurpsy.2010.07.009

11. Baca Baldomero E, Cabanas Arrate ML, Pérez-Rodríguez MM, Baca-García E (2004) Mental disorders in victims of terrorism and their families. Med Clin (Barc) 122:681-685

12. Salib E, Cortina-Borja M (2009) Effect of 7 July 2005 terrorist attacks in London on suicide in England and Wales. Br J Psychiatry $194: 80-85$

13. Suryani LK, Page A, Lesmana CB, Jennaway M, Basudewa ID, Taylor R (2009) Suicide in paradise: aftermath of the Bali bombings. Psychol Med 39:1317-1323

14. Frank E (2005) Funding the public health response to terrorism. BMJ 331:526-527

15. Mass casualties incidents: a framework for planning (2007) Department of Health, Emergency Preparedness Division. Available at:http://www.dh.gov.uk/prod_consum_dh/groups/dh_ digitalassets/@dh/@en/documents/digitalasset/dh_073397.pdf Accessed 16 September, 2011

16. Kaiser J (2011) Taking stock of the biodefense boom. Science 333:1214-1215 